\title{
Plasma cells increased markedly in lymph node in hemophagocytic syndrome: a case report Li Congyang*1, Hu Xuexin ${ }^{1}$, Li Hao $^{2}$, Li Chunge ${ }^{3}$ and Miao Yingye ${ }^{2}$
}

\author{
Address: ${ }^{1}$ Department of Pathology, People's Liberation Army 152 hospital, Pingdingshan City, Henan province, PR China, ${ }^{2}$ Department of \\ Clinical Laboratories, People's Liberation Army 152 hospital, Pingdingshan City, Henan province, PR China and ${ }^{3}$ Department of Pathology, \\ Pingdingshan First People's Hospital, Pingdingshan City, Henan province, PR China \\ Email: Li Congyang* - limeiwai@sohu.com; Hu Xuexin - hxx152@sohu.com; Li Hao - 2008pdslh@163.com; \\ Li Chunge - zhouyili@chye.com.cn; Miao Yingye - myy7591@sina.com \\ * Corresponding author
}

Published: 27 November 2009

Cases Journal 2009, 2:9096 doi:10.1 186/1757-1626-2-9096

This article is available from: http://www.casesjournal.com/content/2/I/9096

This is an Open Access article distributed under the terms of the Creative Commons Attribution License (http://creativecommons.org/licenses/by/2.0), which permits unrestricted use, distribution, and reproduction in any medium, provided the original work is properly cited.

\begin{abstract}
Introduction: Hemophagocytic syndrome is a rare clinicopathological condition characterized by the activation of the mononuclear phagocyte system, resulting in hemophagocytosis in the reticuloendothelial systems. The pathogenesis of HPS remains unclear.
\end{abstract}

Case presentation: We report the case of a 20 -year-old soldier suffering from HPS. Because of long history fever and no reasons being found, his left groin lymph node and left neck lymph node biopsy were done with two weeks interval. We found a marked increase in plasma cells in left neck lymph node during the course of the disease.

Conclusion: Our result provides a new thought for the researchers to understand the mechanisms responsible for the phagocytosis in HPS.

\section{Introduction}

Hemophagocytic syndrome (HPS) is a rare entity characterized by the dysfunction of cytotoxic T cells (CTL) and natural killer (NK) cells, and the activation of the mononuclear phagocyte system $[1,2]$. Its clinical symptoms include long-term high fever, cytopenias, hepatosplenomegaly, lymphadenopathy, and coagulopathy. HPS is divided into primary and secondary HPS, both of which are trigged by acute infections [3]. The pathophysiology of HPS is very complex, but most researchers now believe that it involves the dysregulation of CTLs and activation of the mononuclear phagocyte system (MPS). In the HPS patient phagocytosis of blood cells is a very complex process and may be related to the production of specific immunoglobulins [1,3-5]. In the current case, we found that plasma cells increased markedly in left neck lymph node during the progression of HPS. This observation supports the idea that antibody responses against blood cells may play an important role in the progression of HPS.

\section{Case presentation}

A 20-year-old enlisted man presented with a 1-month history of discontinuous fever, panic, and hypodynamia, and was admitted to People's Liberation Army 152 hospital in May 2008. He had no other complaints. The patient had previously been healthy, with no history of infectious diseases or allergies to food or drugs. Physical examination showed a temperature of $37.3^{\circ} \mathrm{C}$ and no other remarkable signs. Laboratory measurements and examinations revealed no abnormalities. On admission, the patient was administered broad spectrum antibiotics and antiviral 

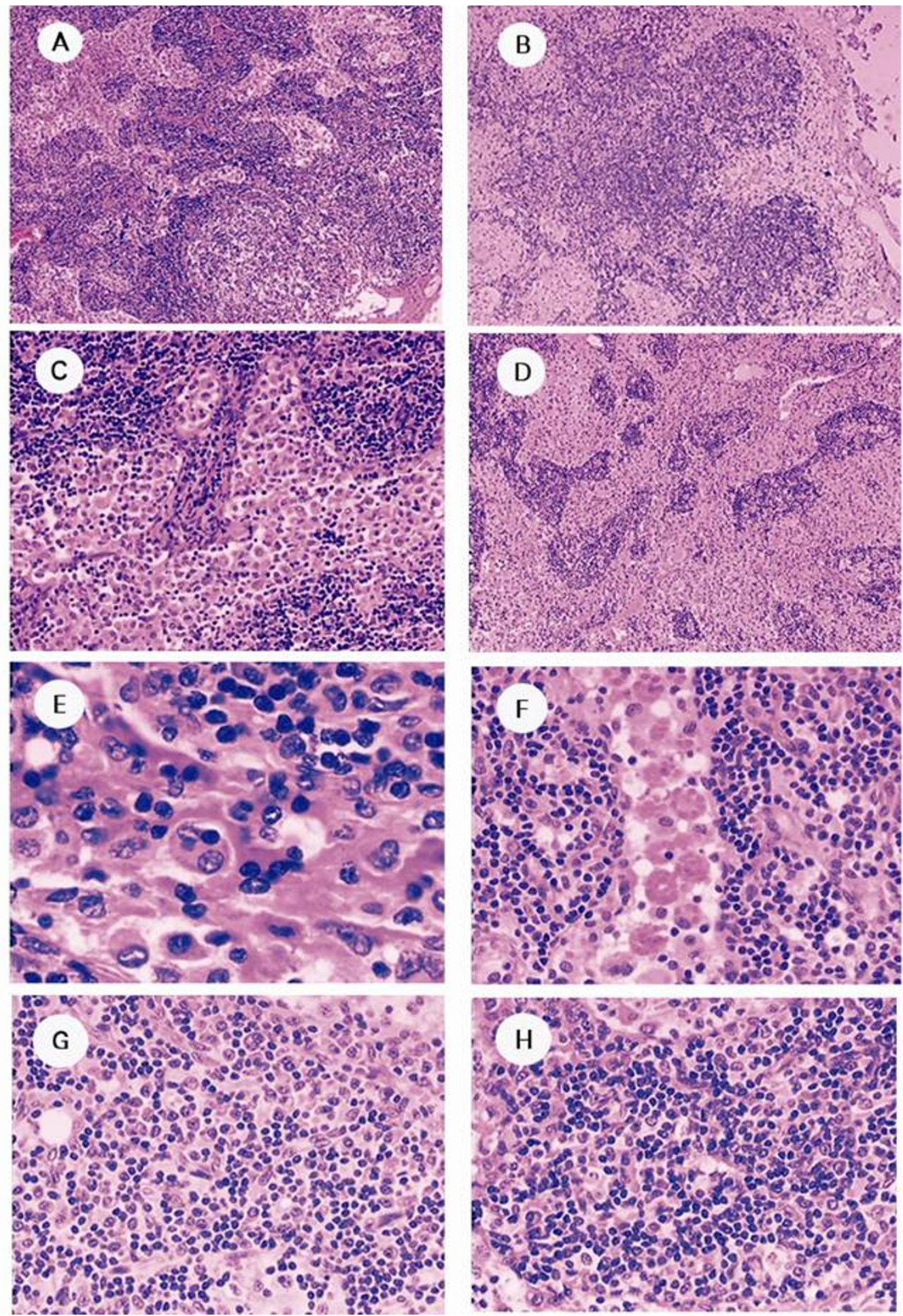

Figure I

Hematoxylin and eosin-stained groin and cervical lymph nodes. A and B, architecture of the groin and cervical lymph nodes, respectively $(\times 40)$. $C$ and $D$, sinus expansion and histiocytes in the groin and cervical lymph nodes, respectively $(\times 100)$. $E$, a macrophage engulfing a blood cell $(\times 400)$. F, many macrophages engulfing many blood cells $(\times 400)$. G, about six plasma cells in the medullary cord of the groin lymph node $(\times 200)$. $\mathrm{H}$, more than 20 plasma cells in the medullary cord of the cervical lymph node $(\times 200)$. 
drugs. However, his fever failed to resolve and his temperature rose to between $38.5^{\circ} \mathrm{C}$ and $40.9^{\circ} \mathrm{C}$. More than 2 weeks later, lymphadenopathy of the left neck, armpit, and left groin was detected by ultrasound. Left groin lymph node and bone marrow puncture biopsies were performed. Histopathological examination of the groin lymph node showed reactive hyperplasia and revealed one histiocyte engulfing few blood cells (Figure. 1E). The bone marrow smear showed no remarkable results. On admission, we cultured for bacteria, parasites, and fungi, and tested for antibodies to hepatitis A virus (HAV), hepatitis B virus (HBV), hepatitis C virus (HCV), human immunodeficiency virus (HIV), treponema pallidum, chlamydia pneumoniae (CP), mycoplasma (MP), respiratory syncytial virus (RSV), and adenovirus (Adv), however, we were unable to detect the triggering agent. One month later, laboratory tests produced the following values: white blood cell count $1.60 \times 10^{9} / \mathrm{L}$, red blood cell $3.42 \times 10^{12} / \mathrm{L}$, hemoglobin $107 \mathrm{~g} / \mathrm{L}$, platelet count $156 \times$ $10^{9} / \mathrm{L}$, fibrinogen $0.67 \mathrm{~g} / \mathrm{L}$, triglyceride $13.9 \mathrm{mmol} / \mathrm{L}$ (Table 1). Ultrasound examination revealed hepatosplenomegaly.

Left neck lymph node biopsy and bone marrow puncture smear were performed. The results were characteristic of HPS (Figure. 1F and Figure. 2). The germinal centers were unclear in both the groin and cervical lymph nodes, and the lymph nodes retained normal structure, except for sinusoidal expansion (Figure. 1A, B). Broadening of the sinuses in the groin lymph node was mainly detected in the medullary area, where they were filled with histiocytes (Figure. 1C). In the cervical lymph node, the subcapsular, peritrabecular and medullary sinuses were expanded and filled with activated histiocytes that were seen to be phagocytosing blood cells (Figure. 1D, Figure 1F). Plasma cell counts averaged 8/high power field (HPF) in the medullary cord of the groin lymph node, while they averaged 17/HPF in the cervical lymph node (Figure 1G, Figure $1 \mathrm{H})$. Treatment was administered according to the Hemophagocytic Lymphohistiocytosis (HLH) 2004 protocol [6], with proper alternation (cyclophosphamide, perarubicin, vincristine sulfate, dexamethasone and etoposide), but the patient suffered multiple organ dysfunction syndrome after therapy, and died from pulmonary infection 2 month later.

\section{Discussion}

HPS is a life-threatening condition characterized by the activation of the MPS. It can be divided into genetic HPS and secondary HPS [2]. Genetic HPS can result from autosomal defects, or can also be associated with immune deficiencies, such as Chediak-Higashi syndrome, X-linked lymphoproliferative syndrome, and Griscelli syndrome. Secondary HPS is associated with exogenous agents (including viruses, bacteria, fungi, parasites, and toxins),
Table I: Laboratory findings on admission

\begin{tabular}{|c|c|c|c|}
\hline \multicolumn{2}{|c|}{ Blood cell counts } & \multicolumn{2}{|l|}{ Coagulation } \\
\hline WBC & $0.80 \times 10^{9} / \mathrm{L}$ & PT & $22.4 \mathrm{sec}$ \\
\hline RBC & $3.42 \times 10^{12 / L}$ & INR & 2.00 \\
\hline HGB & $107 \mathrm{~g} / \mathrm{L}$ & $\mathrm{TT}$ & $24.2 \mathrm{sec}$ \\
\hline \multirow[t]{2}{*}{ PLT } & $156 \times 10^{9} / \mathrm{L}$ & APTT & $42.7 \mathrm{~g} / \mathrm{L}$ \\
\hline & & FIG & $0.67 \mathrm{~g} / \mathrm{L}$ \\
\hline \multicolumn{4}{|c|}{ Blood chemistry } \\
\hline TP & $55.50 \mathrm{~g} / \mathrm{L}$ & CK-MB & $32 \mathrm{U} / \mathrm{L}$ \\
\hline ALB & $26.60 \mathrm{~g} / \mathrm{L}$ & $\mathrm{HBDH}$ & $1929 \mathrm{U} / \mathrm{L}$ \\
\hline GLOB & $28.9 \mathrm{~g} / \mathrm{L}$ & $\mathrm{LDH}$ & $2467 U / L$ \\
\hline DB & $201.11 \mu \mathrm{mol} / \mathrm{L}$ & TG & $13.9 \mathrm{mmol} / \mathrm{L}$ \\
\hline IB & $24.73 \mu \mathrm{mol} / \mathrm{L}$ & Urine $\beta_{2}-M G$ & $16.5 \mathrm{mg} / \mathrm{L}$ \\
\hline GOT & $390 \mathrm{U} / \mathrm{L}$ & Blood $\beta_{2}-M G$ & $5.8 \mathrm{mg} / \mathrm{L}$ \\
\hline$\gamma$-GT & $173.00 \mathrm{U} / \mathrm{L}$ & CRP & $244 \mathrm{mg} / \mathrm{L}$ \\
\hline CK & $458 \mathrm{U} / \mathrm{L}$ & ALP & $208.0 \mathrm{U} / \mathrm{L}$ \\
\hline
\end{tabular}

endogenous products (including those resulting from tissue damage, metabolic products, free radical stress), rheumatic diseases, and malignant diseases $[2,7,8]$. In the current case, we were unable to detect the triggering agent, despite culturing for bacteria, parasites, and fungi, and testing for antibodies to HAV, HBV, HCV, HIV, treponema pallidum, CP, MP, RSV, and Adv, and the patient's fever failed to resolve despite treatment with broad-spectrum antibiotics and antiviral drugs. We found no association between drug use and HPS. A diagnosis of lymphoma was eliminated because of the tissue structure and immunoarchitecture.

Although progress has been made in understanding the pathophysiology of HPS, the exact mechanisms responsi-

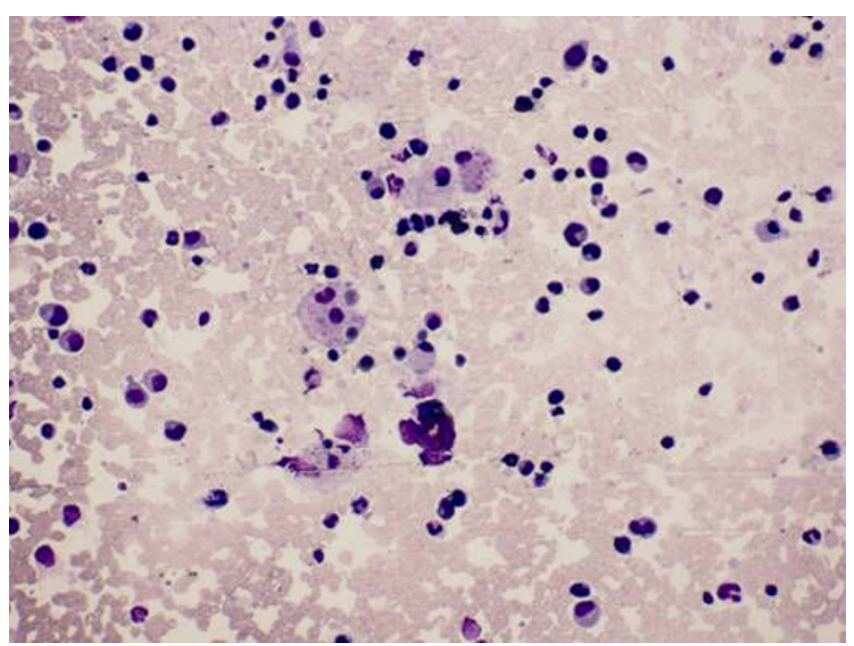

\section{Figure 2}

Bone marrow smear showing macrophages engulfing lymphocytes and red blood cells (Wright's stain $\times 200$ ). 
ble for the phagocytosis are unknown in HPS. Researchers found out that there have the RBC antibodies in the EBVHPS and anti-RBC antibodies were involved in the phagocytosis of RBCs by macrophages [1]. Also several other researchers have demonstrated that virus infection can induce antibody responses against RBCs, platelets, lymphocytes, and endothelial cells $[5,9]$. As we known the antibodies are produced by the plasma cells. However there has no reports about the exactly changes of plasma cells in HPS patients. In our case the number of plasma cells was markedly increased from $8 / \mathrm{HPF}$ in the groin lymph node to $17 / \mathrm{HPF}$ in the cervical lymph node during the disease progression. Although we didn't detect changes of special antibodies against blood cells, this observation maybe provide a new idea for researchers to study the pathophysiology of HPS.

\section{Conclusion}

This case report showed plasma cells increased markedly in the left neck node during the progression of HPS. The result maybe provide one way to study the pathophysiology of the HPS.

\section{Abbreviations}

HPS: hemophagocytic syndrome; CTL: cytotoxic T cells; MPS: mononuclear phagocyte system; HAV: hepatitis A virus; HBV: hepatitis B virus; HCV: hepatitis C virus; HIV: human immunodeficiency virus; $\mathrm{CP}$ : chlamydia pneumoniae; MP: mycoplasma; RSV: respiratory syncytial virus; Adv: adenovirus; WBC: white blood cell count; RBC: red blood cell; HGB: hemoglobin; PLT: platelet count; PT: prothrombin time; NR: international normalized ratio; TT: thrombin time; APTT: activated partial thromboplastin time; FIG: fibrinogen; TP: total protein; ALB: albumin; GLOB: globulin; DB: direct bilirubin; IB: indirect bilirubin; $\gamma$-GT: $\gamma$-glutamyl transpeptidase; CK: creatine kinase; CK-MB: creatine kinase-MB; HBDH: hydroxybutyrate dehydrogenase; LDH: lactate dehydrogenase; TG: triglyceride; $\beta 2$-MG: $\beta 2$-microglolulin; CRP: C-reactive protein; ALP: alkaline phosphatase.

\section{Consent}

Written informed consent was obtained from the patient' older brother for publication of this case report and accompanying images. A copy of the written consent is available for review by the Editor-in-Chief of this Journal.

\section{Competing interests}

The authors declare that they have no competing interests.

\section{Authors' contributions}

$\mathrm{L} C Y$ and $\mathrm{M}$ YY interpreted the data, operated on the patient and wrote the manuscript. L CG performed the histological examination. H XX reviewed the paper. All authors read and approved the final manuscript.

\section{References}

I. Hsieh WC, Chang Y, Hsu MC, Lan BS, Hsiao GC, Chuang HC, Su II: Emergence of anti-red blood cell antibodies triggers red cell phagocytosis by activated macrophages in a rabbit model of Epstein-Barr virus-associated hemophagocytic syndrome. Am J Pathol 2007, 170:1629-1639.

2. Janka G, Zur Stadt U: Familial and acquired hemophagocytic lymphohistocytosis. Hematology Am Soc Hematol Educ Program 2005:82-88.

3. Fisman DN: Hemophagocytic syndromes and infection. Emerg Infect Dis 2000, 6:60I-608.

4. Kereveur A, Mcllroy D, Samri A, Oksenhendler E, Clauvel JP, Autran $B$ : Up-regulation of adhesion and MHC molecules on splenic monocyte/macrophages in adult haemophagocytic syndrome. BrJ Haematol 1999, 104:87I-877.

5. Toyoshige M, Takahashi H: Increase of platelet-associated IgG (PA-IgG) and hemophagocytosis of neutrophils and platelets in parvovirus B 19 infection. Int J Hematol 1998, 67:205-206.

6. Henter JI, Horne A, Arico M, Egeler RM, Filipovich AH, Imashuku S, Ladisch S, McClain K, Webb D, Winiarski J, Janka G: HLH-2004: Diagnostic and therapeutic guidelines for hemophagocytic lymphohistiocytosis. Pediatr Blood Cancer 2007, 48: I 24-I3I.

7. Henter JI, Ehrnst A, Andersson J, Elinder G: Familial hemophagocytic lymphohistiocytosis and viral infections. Acta Paediatr 1993, 82:369-372.

8. Kaito K, Otsubo H, Takei Y: Immunosuppressive therapy with antithymocyte globulin and cyclosporine for prolonged marrow failure after hemophagocytic syndrome. Ann Hematol 82:699-701.

9. Papesch M, Watkins R: Epstein-Barr virus infectious mononucleosis. Clin Otolaryngol Allied Sci 200I, 26:3-8.

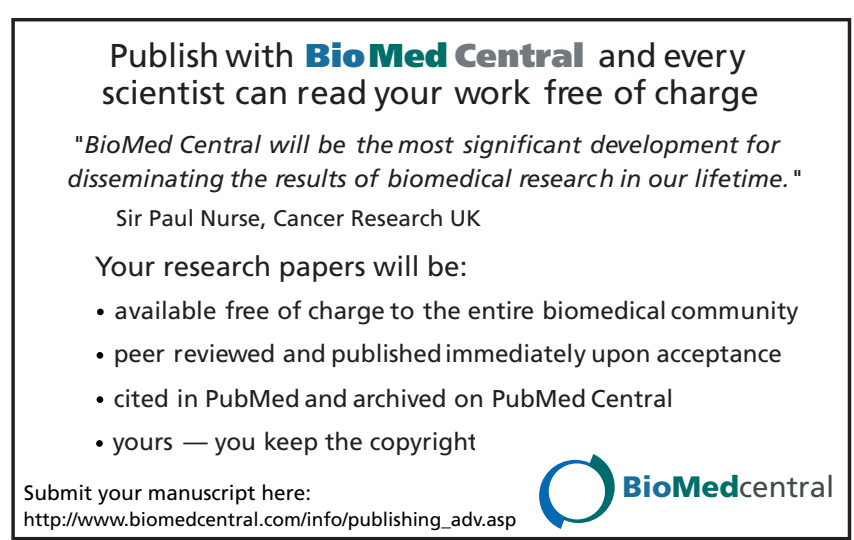

